\title{
DR. 2292
}

Beam Profiles from Multiple Aperture Sources

J. H. Whealton 


\section{DISCLAIMER}

This report was prepared as an account of work sponsored by an agency of the United States Government. Neither the United States Government nor any agency Thereof, nor any of their employees, makes any warranty, express or implied, or assumes any legal liability or responsibility for the accuracy, completeness, or usefulness of any information, apparatus, product, or process disclosed, or represents that its use would not infringe privately owned rights. Reference herein to any specific commercial product, process, or service by trade name, trademark, manufacturer, or otherwise does not necessarily constitute or imply its endorsement, recommendation, or favoring by the United States Government or any agency thereof. The views and opinions of authors expressed herein do not necessarily state or reflect those of the United States Government or any agency thereof. 


\section{DISCLAIMER}

Portions of this document may be illegible in electronic image products. Images are produced from the best available original document. 
Printed in the United States of America. Available from National Technical Information Service

U.S. Department of Commerce

5285 Port Royal Road, Springfield, Virginia 22161

Price: Printed Copy $\$ 4.00$; Microfiche $\$ 3.00$

This report was prepared as an account of work sponsored by an agency of the United States Government. Neither the United States Government nor any agency thereof, nor any of their employees, contractors, subcontractors, or their employees, makes any warranty, express or implied, nor assumes any legal liability or responsibility for any third party's use or the results of such use of any information, apparatus, product or process disclosed in this report, nor represents that its use by such third party would not infringe privately owned rights. 
ORNL/TM-6421

Dist. Category UC-20 a

Contract No. W-7405-eng-26

FUSION ENERGY DIVISION

BEAM PROFILES FROM MULTIPLE APERTURE SOURCES

J. H. Whealton

Date Published: February, 1979

This report was prepared as an account of work sponsored by the United States Govemment. Neither the

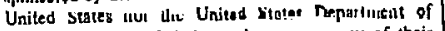
Energy, nor any of their emplayees, nor any of their contractors, subcontractors, or their employees, makes any warranty, express or implied, or assumes any legal liability or responsibility for the accuracy. completeness or usefulness of any information, apparatus, produet or process disclosed, or represents that its wse would not infringe privately owned rights.

NOTICE This document contains information of a preliminary nature.

It is subject to revision or correction and thereforc docs not represent a final report.

Prepared by the

OAK RIDGE NATIONAL LABORATORY

Oak Ridge, Tennessee 37830

operated by

UNION CARBIDE CORPORATION

for the

DE'PAK'LMENT OF ENERGY 


\section{THIS PAGE}

\section{WAS INTENTIONALLY \\ LEFT BLANK}




\begin{abstract}
Using a rapidly convergent approximation scheme, formulas are given for beam intensity profiles everywhere. In first approximation, formulas are found for multiple aperture sources, such as a TFTR design, and integrated power for rectangular plates downstream for Gaussian beamlets. This analysis is duplicated for Lorentzian beamlets which should provide a probable upper bound for off-axis loading as Gaussian beamlets provide a probable lower bound. Formulas. for beam intensity profiles are found everywhere. In first approximation, formulas are found for downstream intensity of multiple sources and integrated power for rectangular plates.
\end{abstract}


Previous analysis ${ }^{1}$ includes formulas for the beam power intensity for Gaussian beamlets at (a) the focal plane, (b) on the beam axis, and (c) very near the beam axis. By considering a rapidly convergent approximation scheme these, results are extended to give beam power intensities everywhere and, in first approximation, beam intensities everywhere for multiple, but closely spaced, sources. Total beam power deposited on a rectangular plate is also given.

Consider the coordinate system and approximation scheme shown in Fig. I where the circular source is approximated by a square one. The intensity at a point $\zeta, \eta, \xi$ from an element in the source is

$$
\operatorname{di}(\zeta, n, \xi)=\frac{1}{\pi(\xi, \theta)^{2}} \exp \left[-\frac{\left(\zeta^{2}+\eta^{2}\right)}{(\xi, \theta)^{2}}\right] \mathrm{d} \zeta \mathrm{d} \eta
$$

and the intensity at a point $\zeta, n, \xi$ from the entire source, in first approximation, is

$$
1_{1}(\zeta, \eta, \xi)=\frac{1}{\pi(\xi \theta)^{2}} \int_{-1 / 2}^{+1 / 2} \mathrm{~d} \zeta^{\cdot} \int_{-1 / 2}^{+1 / 2} \mathrm{~d} \eta^{\cdot} \exp \left[-\frac{\left(\zeta^{\prime}-\zeta\right)^{2}+\left(\eta^{\prime}-\eta\right)^{2}}{(\xi \theta)^{2}}\right] .
$$

Integration gives the result:

$$
\begin{aligned}
i_{1}(\zeta, n, \xi) & =\frac{1}{4}\left[\operatorname{erf}\left(\frac{1-2 \zeta}{2 \xi \theta}\right)+\operatorname{erf}\left(\frac{1+2 \zeta}{2 \xi \theta}\right)\right] \\
& \times\left[\operatorname{erf}\left(\frac{1-2 n}{2 \xi \theta}\right)+\operatorname{erf}\left(\frac{1+2 n}{2 \xi \theta}\right)\right] .
\end{aligned}
$$

If focusing is considered as in the above figure, $i$ is divided by $(1-\xi / \lambda)^{2}$ and the limits of integration in Eq. (2) are multiplied by $1-\xi / \lambda$ giving the result, in first approximation, 


$$
\begin{aligned}
i_{1}(\zeta, n, \xi) & =\frac{\lambda^{2}}{4(\lambda-\xi)^{2}}\left\{\operatorname{erf}\left[\frac{\lambda(1-2 \zeta)-\xi}{2 \lambda \xi \theta}\right]+\operatorname{erf}\left[\frac{\lambda(1+2 \zeta)-\xi}{2 \lambda \xi \theta}\right]\right\} \\
& \times\left\{\operatorname{erf}\left[\frac{\lambda(1-2 n)-\xi}{2 \lambda \xi \theta}\right]+\operatorname{erf}\left[\frac{\lambda(1+2 n)-\xi}{2 \lambda \xi \theta}\right]\right\},
\end{aligned}
$$

which at the focal plane, using the asymptotic properties of the error function, becomes in any approximation

$i(\zeta, n, \lambda)=\frac{1}{\pi(\xi A)^{2}} \exp \left[-\frac{\zeta^{2}+1^{2}}{(\xi A)^{2}}\right]$,

in agreement with previous analysis. ${ }^{1}$ On the axis the intensity becomes in first approximation

$i_{1}(0,0, \xi)=\frac{\lambda^{2}}{(\lambda-\xi)^{2}}\left[\operatorname{erf}\left(\frac{\lambda-\xi}{2 \lambda \xi \theta}\right)\right]^{2}$,

in contrast with the exact results in the previous analysis,

$1(0,0, \xi)=\frac{\lambda^{2}}{(\lambda-\xi)^{2}}\left\{1-\exp \left[-\frac{(\lambda-\xi)^{2}}{\pi(\lambda \xi \theta)^{2}}\right]\right\}$.

In second approximation, as shown in Fig. 1, two square sources are considered at $45^{\circ}$ to each other. 'l'he result it

$i_{2}(\zeta, n, \xi)=\frac{1}{2} i_{1}(\zeta, n, \xi)+\frac{1}{2} i_{1}\left(\frac{\zeta+n}{\sqrt{2}}, \frac{n-\zeta}{\sqrt{2}}, \xi\right)$,

and so on for the $\mathrm{n}^{\text {th }}$ approximation,

$i_{n}(\zeta, n, \xi)=\frac{1}{n} \sum_{m=0}^{n-j} i_{1}\left(\zeta \cos \frac{m \pi}{2 n}+n \sin \frac{m \pi}{2 n}, 1 \cos \frac{m \pi}{2 n}-\zeta \sin \frac{m \pi}{2 n},\right)$

For multiple sources (e.g., three) the total beam intensity at a point is in first approximation:

$$
i_{I I I}(\zeta, n, \xi)=i_{1}(\zeta, n, \xi)+i_{1}[\zeta, n-\alpha(\lambda-\xi), \xi]+i_{1}[\zeta, n+\alpha(\lambda-\xi), \xi],
$$


ORNL DWG 79-2033 FED
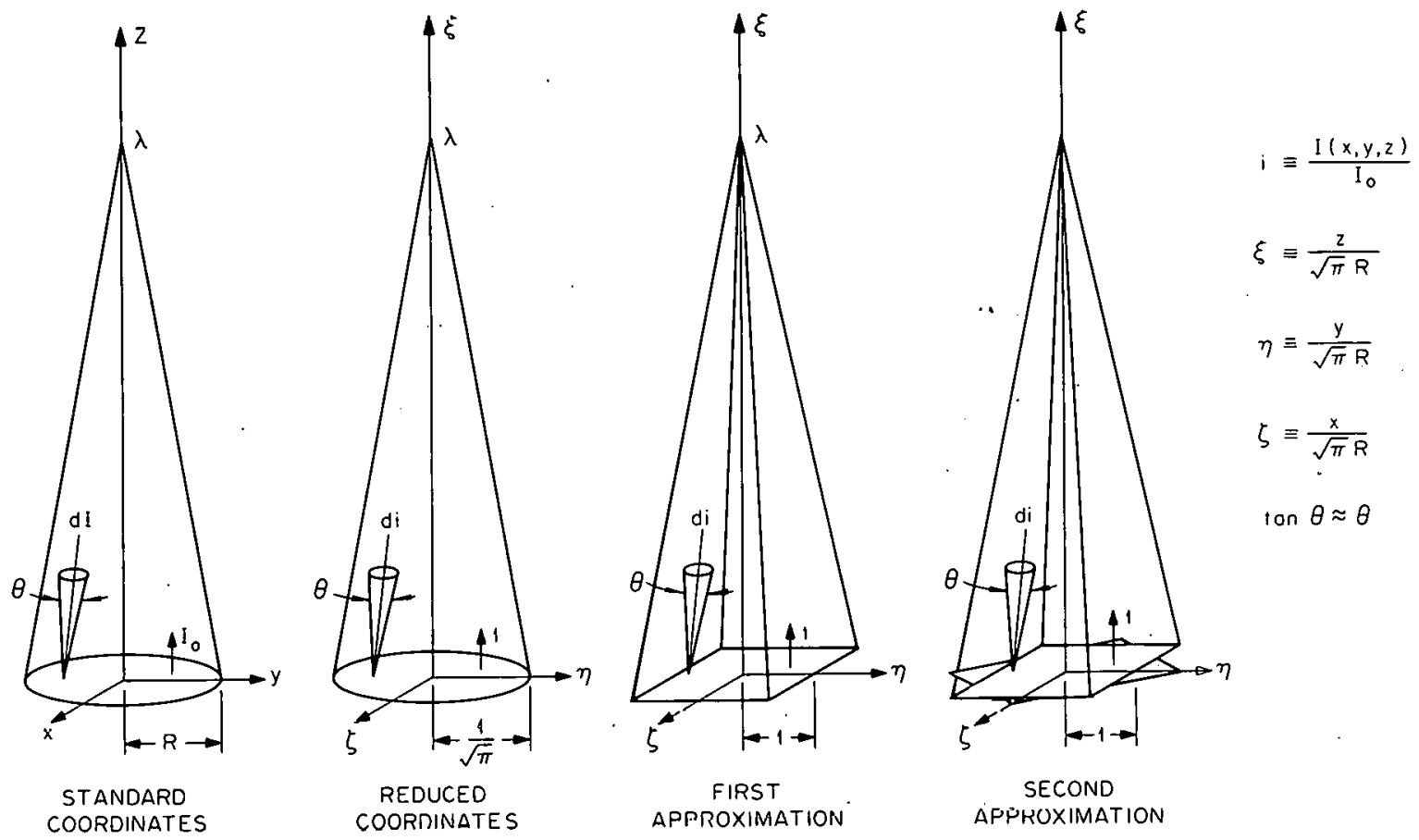

Fig. 1. The square peg in a round hole approximation scheme. 
where the configuration of the three sources is shown in Fig. 2 .

Finally the integrated power is computed from a single source in first approximation over the hatched area in Fig. 3, which is

$$
\int_{\beta}^{\infty} \mathrm{d} \zeta \int_{-\gamma}^{+\gamma} \mathrm{dn} i_{1}(\zeta, n, \xi)=\frac{\lambda^{2}}{2(\lambda-\xi)^{2}} \mathrm{~g}(\gamma) \mathrm{g}(-\beta)
$$

where

$$
\begin{aligned}
g(\gamma) & =\xi \theta\left(\left[\frac{\lambda(1+2 \gamma)}{2 \lambda \xi \theta}-\zeta\right] \text { orf }\left[\frac{\lambda(1+2 \gamma)-\xi}{2 \lambda \xi \theta}\right]\right. \\
& -\left[\frac{\lambda(1-2 \gamma)-\xi}{2 \lambda \xi \theta}\right] \operatorname{erf}\left[\frac{\lambda(1-2 \gamma)-\xi}{2 \lambda \xi \theta}\right]-\frac{1}{\sqrt{\pi}} \exp \left\{-\left[\frac{\lambda(1+2 \gamma)-\xi}{2 \lambda \xi \theta}\right]^{2}\right\} \\
& \left.+\frac{1}{\sqrt{\pi}} \exp \left\{-\left[\frac{\lambda(1-2 \gamma)-\xi}{2 \lambda \zeta \theta}\right]^{2}\right\}\right)
\end{aligned}
$$

the extension to three sources being obvious.

The inaccuracy of the first approximation is clearly very small near the focal plane and larger outside.

Perhaps it is worthwhile to note that the analysis in first approximation is diractly applicable to the Berkeley source providing that the tensoral divergence angle is Included by starting from $\mathrm{d} 1(\zeta, n, r)=\frac{1}{\pi \theta_{\|}{ }_{1} \xi^{2}} \exp \left[-\left(\frac{\zeta^{2}}{\theta_{\| \xi^{2}}}+\frac{\eta^{2}}{\theta_{\perp} \xi^{2}}\right)\right] \mathrm{d} \| \mathrm{d} \zeta$, instead of Eq. (1).

An asaumption in the foregoing is that individual beamlets have a Gaussian profile. Since such a profile has a very rapid off-axis falloff and since certain beam line designs may depend on wall loading, a Lorentzian beamlet profile is considered. A Lorentzian proftle falls off more slowly off-axis as is seen in Fig. 4. The same approximation scheme and analysis as mentioned above is presented below for Lorentzian beamlets. 
ORNL DWG 79-2034 FED

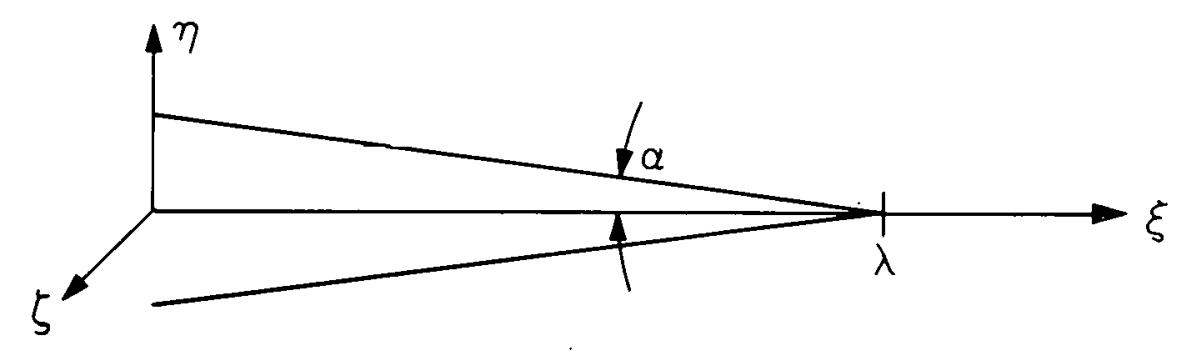

Fig. 2. Three source configuration.

ORNL DWG 79-2035 FED

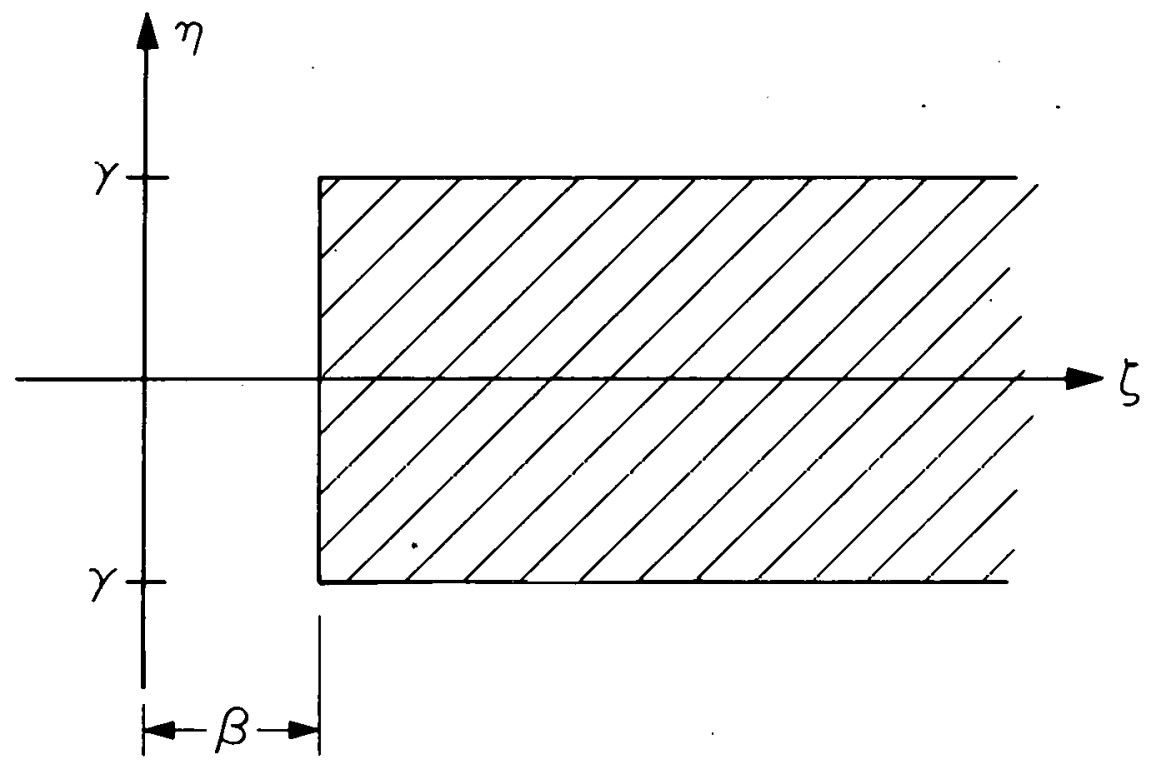

Fig. 3. Region of total power computation. 


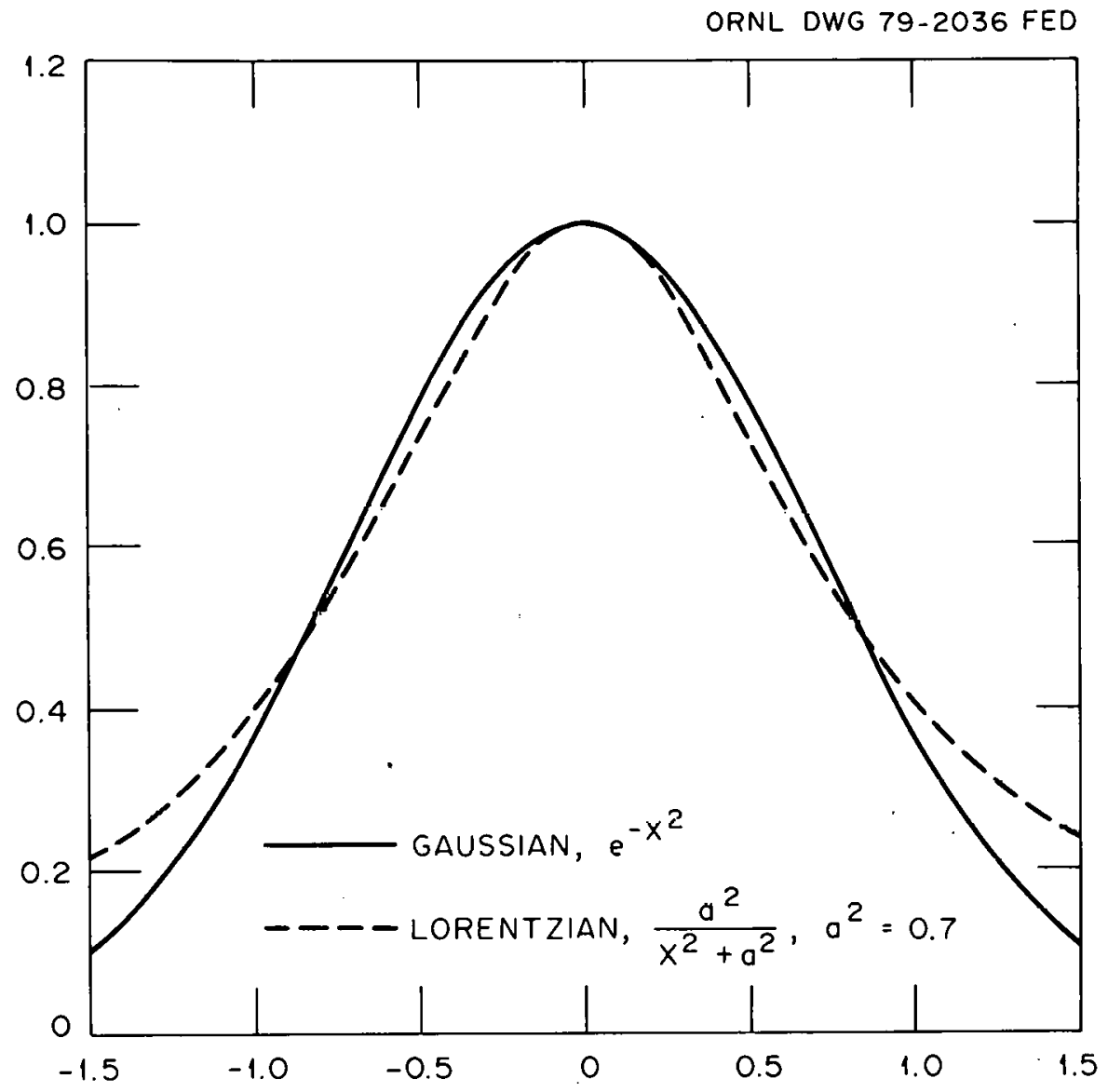

Fig. 4. Comparison of Gaussian and Lorentzian. 
Consider the coordinate system and approximation scheme as shown in Fig. 1 where the circular source is approximated by a square one. The intensity at a point $\zeta, n, \xi$ from an element in the source is

$\operatorname{di}(\zeta, n, \xi)=\frac{(\xi \theta / \pi)^{2}}{\left(\zeta^{2}+\xi^{2} \theta^{2}\right)\left(\eta^{2}+\xi^{2} \theta^{2}\right)} d \zeta d \eta$,

where the divergence angle $\theta$ is the half max angle of the Lorentzian distribution along one axis. The beamlet distribution is not quite cylindrically symmetric but this artifact washes out in higher approximations. The intensity at a point $\zeta, n, \xi$ from the entire-source, in first approximation, is

$$
\begin{aligned}
i_{1}(\zeta, \eta, \xi) & =\left(\frac{\xi \theta}{\pi}\right)^{2} \int_{-1 / 2}^{+1 / 2} \mathrm{~d} \zeta^{\prime} \int_{-1 / 2}^{+1 / 2} \mathrm{~d} \eta^{\prime}\left[\left(\zeta^{\prime}-\zeta\right)^{2}+\xi^{2} \theta^{2}\right]^{-1} \\
& \times\left[\left(\eta^{\prime}-\eta\right)^{2}+\xi^{2} \theta^{2}\right]^{-1} .
\end{aligned}
$$

Integration gives the result:

$$
\begin{aligned}
i_{1}(\zeta, n, \xi)=\frac{1}{\pi^{2}} & {\left[\arctan \left(\frac{1-2 \zeta}{2 \xi \theta}\right)+\arctan \left(\frac{1+2 \zeta}{2 \xi \theta}\right)\right] } \\
\times & {\left[\arctan \left(\frac{1-2 n}{2 \xi \theta}\right)+\arctan \left(\frac{1+2 n}{2 \xi \theta}\right)\right] . }
\end{aligned}
$$

If focusing is considered as in Fig. $1, i$ is divided by $(1-\xi \lambda)^{2}$ and the limits of integration in Eq. (14) are multiplied by $1-\xi / \lambda$ giving the result

$$
\begin{array}{r}
i_{1}(\zeta, n, \xi)=\frac{(\lambda / \pi)^{2}}{(\lambda-\xi)^{2}}\left\{\arctan \left[\frac{\lambda(1-2 \zeta)-\xi}{2 \lambda \xi \theta}\right]+\arctan \left[\frac{\lambda(1+2 \zeta)-\xi}{2 n \xi \theta}\right]\right\} \\
\times\left\{\arctan \left[\frac{\lambda(1-2 n)-\xi}{2 \lambda \xi \theta}\right]+\arctan \left[\frac{\lambda(1+2 n)-\xi}{2 \lambda \xi \theta}\right]\right\}
\end{array}
$$


which at the focal plane using the asymptotic properties of the arc tangent becomes

$i_{1}(\zeta, n, \lambda)=\frac{(\lambda / \pi)^{2}}{\left(\zeta^{2}+\lambda^{2} \theta^{2}\right)\left(\eta^{2}+\lambda^{2} \theta^{2}\right)}$.

On the axis the intensity becomes in first approximation

$i_{1}(0,0, \xi)=\frac{4(\lambda / \pi)^{2}}{(\lambda-\xi)^{2}}\left[\arctan \left(\frac{\lambda-\xi}{2 \lambda \xi \theta}\right)\right]^{2}$.

In second approximation two square sources are considered at $45^{\circ}$ to each other, as shown in Fig. 1.

For multiple sources (e.g., three) the total beam intensity at a point is approximately in first approximation by Eq. (10) where the configuration of the three sources is shown in Fig. 2 .

Finally the integrated power is computer from a single source in first

$$
\begin{aligned}
& \int_{\beta}^{\infty} d \zeta \int_{-\gamma}^{+} d n i_{1}(\zeta, n, \xi)=\frac{2(\lambda / \pi)^{2}}{(\lambda)^{2}} g(\gamma) g(-\beta), \\
& g(\gamma)=\xi \theta\left(\left[\frac{\lambda(1+2 \gamma)-\xi}{2 \lambda \xi \theta}\right] \arctan \left[\frac{\lambda(1+2 \gamma)-\xi}{2 \lambda \xi \theta}\right]-\left[\frac{\lambda(1-2 \gamma)-\xi}{2 \lambda \xi \theta}\right]\right. \\
& \quad \times \arctan \left[\frac{\lambda(1-2 \gamma)-\xi}{2 \lambda \xi 0}\right] \\
& -\frac{1}{2} \log \left\{(2 \lambda \xi \theta)^{2}+[\lambda(1+2 \gamma)-\xi]^{2}\right\} \\
& +\frac{1}{2} \log \left\{(2 \lambda \xi \theta)^{2}+[\lambda(1-2 \gamma)-\xi]^{2}\right\}
\end{aligned}
$$

the extension to three sources being obvious.

The inaccuracy of the first approximation is clearly very small near the focal plane and larger outside. 
As with the Gaussian beamlet case, it is worthwhile to note that the analysis in first approximation is directly applicable to the Berkeley source providing that the tensoral divergence angle is included by starting from

$\operatorname{di}(\zeta, n, \xi)=\frac{\xi^{2} \theta_{\|} \theta_{\perp} / \pi^{2}}{\left(\zeta^{2}+\xi^{2} \theta_{\|}^{2}\right)\left(n^{2}+\xi^{2} \theta_{\perp}^{2}\right)} \operatorname{dnd} \zeta$.

This analysis was done in April 1976 and partially reported in Nuclear Instruments and Methods 141,187 (1977). At the time there was little evidence for fatter distributions than Gaussian. However, since that time such evidence has accumulated. In connection with reionization loss calculations accounting for direct beam interception, these calculations assume new importance and this report is issued in response to this demand. 
REFERENCE

1. J. Kim (ORNL) private communication (1975). 
ORNL/TM-6421

Dist. Category UC-20 a

\section{INTERNAL DISTRIBUTION}

1. G. C. Barber
2. C. F. Barnett
3. L. A. Berry
4. C. W. Blue
5. J. D. Callen
6. W. K. Dagenhart
7. R. A. Dand1
8. R. C. Davis
9. C. A. Foster
10. W. L. Gardner
11. H. H. Haselton
12. T. C. Jernigan
13. G. G. Kelley
14. J. Kim
15. M. S. Lubel1
16. M. M. Menon
17. H. C. McCurdy
18. S. L. Milora
19. O. B. Morgan
20. N. S. Ponte

\author{
21. M. Roberts \\ 22. M. W. Rosenthal \\ 23. P. M. Ryan \\ 24. D. E. Schechter \\ 25. S. W. Schwenterly \\ 26. J. Sheffield \\ 27. D. Steiner \\ 28. W. L. Stirling \\ 29. C. C. Tsai \\ 30-59. J. H. Whealton \\ 60. R. E. Wright \\ 61-62. Central Research Library \\ 63. Document Reference Section \\ 64-65. Laboratory Records \\ 66. Laboratory Records, ORNL-RC \\ 67. ORNL Patent Office \\ 68-69. Fusion Energy Division Library \\ 70. Fusion Energy Division \\ Communications Center
}

\section{EXTERNAL DISTRIBUTION}

71. D. J. Anthony, Energy Systems and Technology Division, General Electric Company, 1 River Road, Bldg. 23, Room 2, Schenectady, NY 12345

72. C. Baker, Argonne Nationa1 Laboratory, 9700 South Cass Avenue, Argonne, IL 60439

73. J. W. Beal, General Atomic Company, P.0. Box 608, San Diego, CA 92112

74. J. F. Clarke, Office of Fusion Energy (ETM), U.S. Department of Energy, Washington, DC 20545

75. F. E. Coffman, Office of Fusion Energy (ETM), U.S. Department of Energy, Washington, DC 20545

76. R. W. Conn, Department of Nuclear Engineering, Univers1ty of Wisconsin, Madison, WI 53706

77. S. O. Dean, Office of Fusion Energy (ETM), U.S. Department of Energy, Washington, DC 20545

78. H. P. Eubank, Plasma Physics Laboratory, Princeton University, P.0. Box 451, Princeton, NJ 08540

79. I'. K. Fowler, Lawrence Livermore Laboratory, Universtty of California, P.0. Box 808, Livermore, CA 94550

80. H. K. Forsen, Exxon Nuclear Company, 2955 George Washington Way, Richland, WA 99352

81. H. P. Furth, Plasma Physics Laboratory, Princeton University, P.0. Box 451, Princeton, NJ 08540 
82. R. W. Gould, Electrical Engineering and Physics Department, B1dg. 116-81, California Institute of Technology, Pasadena, CA 91109

83." R. L. Hirsch, Exxon Research and Engineering, P.0. Box 101, Florham Park, NJ 07932

84. Ray Huse, Chairman, EPRI Fusion Program Committee, Public Service Electric and Gas Company, 80 Park Place, Newark, NJ 07101

85. E. E. Kintner, Office of Fusion Energy (ETM), U.S. Department of Energy, Washington, DC 20545

86. S. Matsuda, Japan Atomic Energy Research Institute, Tokai, Ibarak1, Japan

87. Director, Max Planck Instituut für Plasmaphysik, Garching be1 München, Federa1 Republic of Germany

หK. (i. H. Miley, Nuclear Engineering Program, Univoroity of Illino1s, Ürbana, IL 61801

89. T. Ohkawa, General Atomic Company, P.0. Box 608, San Diego, CA 92112

90. R. V. Pyle, Lawrence Berkeley Laboratory, University of California, Berkeley, CA 94120

91. D. J. Rose,' Massachusetts Institute of Technology, James Forrestal Campus, Cambridge, MA 02139

92. N. N. Semasko, Kurchatov Atomic Energy Institute, Moscow, U.S.S.R.

93. T. Sluyters, Brookhaven National Laboratory, Upton, Long Island, NY 11973

94. H. S. Staten, Office of Fusion Energy (ETM), U.S. Department of Energy, Washington, DC 20545

95. L. D. Stewart, Plasma Physics Laboratory, Princeton University, P.o. Box 451, Princeton, NJ 08540

96. E. Thompson, Culham Laboratory, Abingdon, Oxfordshire, United Kingdom

97. P. Ralmbault, Centre d'ttudes Nucleairs, B.P. No. 6, Fontenay-aux-Roses, France

98. J. M. Williams, Office of Fusion Energy (ETM), U.S. Department of Energy, Washington, DC 20545

99. J. T. Woo, Massachusetts Institute of Technology, James Forrestal Campus, Cambridge, M 02139

100. Office of Assistant Manager, Energy Research and Development, Department of Energy, Oak Ridge Operations office, Oak Ridge, TN 37830

101-253. Given distribution as shown in TID-4500, Magnetic Fusion Energy (Distribution Category UC-20 a, Plasma Systems) 